\section{Perforation of the esophagus after dilation treat- ment for dysphagia in a patient with eosinophilic esophagitis}

A 17-year-old girl presented with progressive dysphagia. Congenital esophageal stenosis had been diagnosed 8 years previously on the basis of similar symptoms. After repeated esophageal dilation at that time, she had remained asymptomatic for several years. Achalasia was excluded by manometry, which documented complete lower esophageal sphincter relaxation and uncoordinated contractions. A barium swallow examination showed a long-segment stenosis of the esophagus (Figure 1). Endoscopy revealed a longsegment stenosis, which was dilated to a diameter of $11 \mathrm{~mm}$ to allow multiple biopsies to be taken. Minor bleeding and mucosal tears were observed after the dilation. A check-up gastroscopy showed signs of esophagitis and white pin-point plaques (Figure $\mathbf{2}$ ), and multiple biopsies were taken. Computed tomography showed that there was air in the paraesophageal space, and perforation of the esophagus was assumed (Figure 3 ). Four weeks later, no further extramural air was detected, and the patient remained clinically stable.

Histological analysis identified basalzone hyperplasia with increased intercellular clefts, variable but high numbers of intraepithelial eosinophils, focally exceeding 100 per high-powered field. Focally, the immediate subepithelial stroma also contained numerous eosinophils (Figure 4). No parasites, fungi, or other causes of eosinophilic aggregates were identified, and the patient was therefore diagnosed as having eosinophilic esophagitis.

The endoscopic findings in eosinophilic esophagitis most commonly include mucosal fragility, strictures, whitish papules, and a small-caliber esophagus [1]. Eosinophilic esophagitis is best defined by the presence of eosinophils within the epithelium. The presence of more than 15-20 eosinophils per high-powered field is considered to be diagnostic of eosinophilic esophagitis $[2,3]$.

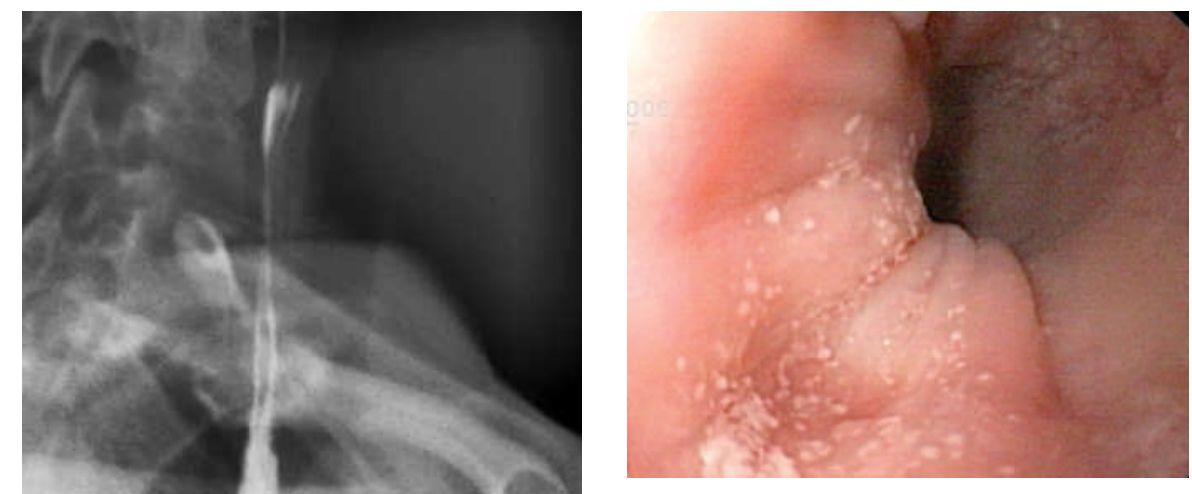

Figure 2 The macroscopic findings at endoscopy. There is no dominant stenosis, but signs of esophagitis and white pin-point plaques were observed.

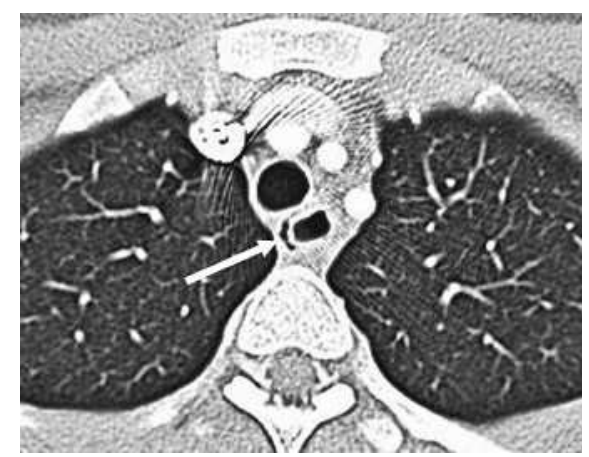

Figure 3 Computed tomography of the esophagus. Air is visible in the paraesophageal space (arrow).

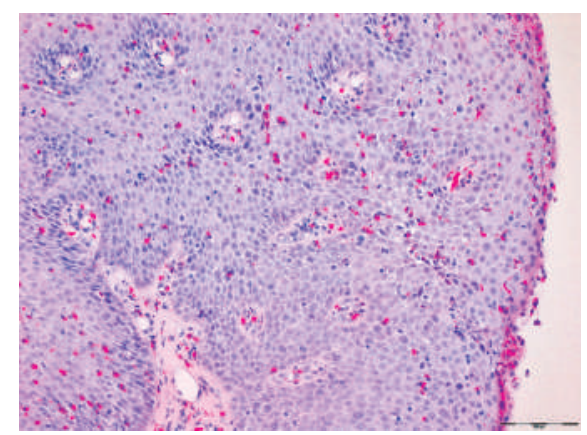

Figure 4 Esophageal biopsy, showing numerous scattered intraepithelial eosinophils (hematoxylin-eosin, original magnification $\times 100)$.

Perforation of the esophagus occurred following dilation. Dilation treatment should be reserved for patients suffering from dysphagia related to the eosinophilic esophagitis who do not respond to medical therapy. Topical steroid treatment has been shown to be safe and effective $[4,5]$. The endoscopic findings in eo- sinophilic esophagitis can be very subtle and easily misinterpreted. In patients presenting with dysphagia in whom proton-

DOI: $10.1055 / \mathrm{s}-2006-944676$ 
pump inhibitor treatment fails, a histological diagnosis should be obtained.

\section{Competing interests: None}

Endoscopy_UCTN_Code_CCL_1AB_2AC_3AD

Endoscopy_UCTN_Code_CPL_1AH_2AF

\section{Eisenbach ${ }^{1}$, U. Merle' ${ }^{1}$,}

P. Schirmacher' ${ }^{2}$, J. Hansmann ${ }^{3}$, A. Stiehl' ${ }^{1}$, W. Stremmel ${ }^{1}$, H. Kulaksiz ${ }^{1}$

${ }^{1}$ Dept. of Gastroenterology, Heidelberg University Hospital, Heidelberg, Germany

2 Dept. of Pathology, Heidelberg University Hospital, Heidelberg, Germany

${ }^{3}$ Dept. of Radiology, Heidelberg University Hospital, Heidelberg, Germany.
References

${ }^{1}$ Sgouros SN, Bergele C, Mantides A. Eosinophilic esophagitis in adults: a systematic review. Eur J Gastroenterol Hepatol 2006; 18: $211-217$

2 Parfitt JR, Gregor JC, Suskin NG et al. Eosinophilic esophagitis in adults: distinguishing features from gastroesophageal reflux disease: a study of 41 patients. Mod Pathol 2006; 19: $90-96$

${ }^{3}$ Fox VL, Nurko S, Furuta GT. Eosinophilic esophagitis: it's not just kid's stuff. Gastrointest Endosc 2002; 56: 260-270

${ }^{4}$ Arora AS, Perrault J, Smyrk TC. Topical corticosteroid treatment of dysphagia due to eosinophilic esophagitis in adults. Mayo Clin Proc 2003; 78: 830-835

${ }^{5}$ Remedios M, Campbell C, Jones DM, Kerlin P. Eosinophilic esophagitis in adults: clinical, endoscopic, histologic findings, and response to treatment with fluticasone propionate. Gastrointest Endosc 2006; 63: 3 -

\section{Corresponding Author}

\section{Eisenbach, M.D.}

Dept. of Gastroenterology Heidelberg University Hospital Im Neuenheimer Feld 410 69120 Heidelberg

Germany

Fax: $\quad+49-6221-566858$

E-mail: Christoph_Eisenbach@ med.uni-heidelberg.de 